\title{
Allium Cepa Ameliorates Ethanol-Induced Gastric Injury in Rats Via Reduction in Gastric Neutrophils Infiltration
}

\author{
${ }^{1 *}$ S.F. Ige, A. O. ${ }^{1}$ Oguntade and ${ }^{2}$ T. Olatunji \\ 1Department of Physiology, Faculty of Basic Medical Sciences, College of Health Sciences, Ladoke Akintola University \\ of Technology, Ogbomoso, Oyo State, Nigeria. \\ 2Department of Physiology, College of Medicine, University of Ibadan, Ibadan, Oyo state, Nigeria \\ [Corresponding author: Email: funkeige2006@yahoo.com; sfige@lautech.edu.ng: +2348060743616]
}

\begin{abstract}
Neutrophil-derived oxygen free radicals have been implicated in the aetiology of gastric tissue damage. In this study, the ameliorative effects of Allium cepa on neutrophil infiltration, lipid peroxidation and antioxidant enzyme activities in the ethanol-induced gastric injury were examined. Twenty four adult male Wistar rats were used for this study and divided into four groups; Control, Allium cepa, Allium cepa + Ethanol and Ethanol. Allium cepa was administered ( $1 \mathrm{~mL} / 100 \mathrm{~g}$ body weight) daily for twenty eight days while $0.2 \mathrm{~mL}$ of $98 \%$ (v/v) ethanol per $23 \mathrm{~g}$ Body Weight was used to induced gastric damage. Macroscopic measurement of ulcer area, histological examination and biochemical analyses (Malondialdehyde level, Myeloperoxidase (index of neutrophil accumulation), Superoxide dismutase (SOD) and Catalase (CAT) activities) were carried out in plasma and gastric tissue. Ethanol administration significantly $(p<0.05)$ increased ulcer score and ulcer index, decreased percentage ulcer inhibition, increased MDA and MPO, decreased SOD and CAT activities. Histological findings show glandular destruction in the gastric mucosa and infiltration of inflammatory cells in ethanol only group. These effects were ameliorated with Allium cepa pre-treatment. The results obtained from this study demonstrate the ameliorative effect of Allium Cepa on ethanol-induced gastric injury by reduction in gastric neutrophils infiltration and increased antioxidant activities.
\end{abstract}

Keywords: Gastric, Allium Cepa, Neutrophil, Myeloperoxidase

\section{INTRODUCTION}

Gastric injury is one of major diseases affecting $5-10 \%$ of people during their life time (Sumbul et al., 2011; Al - Asmari et al., 2016) owning to the fact that the stomach plays major role in the gastrointestinal functions (O'Connor and O'Moráin, 2014). It is opened to wide range of injurious substances such as gastric acid, Helicobacter pylori, non-steroidal antiinflammatory drugs and excessive alcohol (Mowat et al., 1997) which affect the gastric tissue layers.

Reactive oxygen species (ROS) have been implicated in the aetiology of gastrointestinal pathologies, which include gastritis and gastric ulcers (Oliveira et al., 2003; Onasanwo et al., 2011). Characteristic features of gastric injury have been exemplified and it include decreased tissue blood flow, tissue death, neutrophil 2014; Alqasomi, 2015). The use of folk medicine (phytotherapy) has a great therapeutic efficacy and it is affordable. infiltration, inflammatory mediator release and oxidative stress (Viana et al ., 2013). Production of reactive oxygen species and lipid peroxidation have been known to correlate with tissue neutrophil infiltration which has a major association with the degree of tissue damage resulting from ethanol induced gastric tissue damage (Ozer et al ., 2008). Excessive ethanol intake resulted in marked destruction of the gastric tissue (Guslandi, 1987), thus ethanolinduced gastric tissue damage in animal models is widely used to assess the protective ability of majority of drugs used in the treatment of gastric injuries (Hajrezaie et al., 2015; Al Asmari et al., 2016). Meanwhile, much has been reported about the benefits of natural products of herbs in conferring gastro protective benefits owning majorly to their antioxidant properties (Wallace, 2013; Kangwan et al.,

Allium cepa commonly known as "onion" is a member of Liliacea species and is one of the important vegetables consumed daily. Its 
antioxidant properties had been established and ascribed to its constituents such as flavonoids, anthocyanins and dihydroflavonols (Griffiths et al ., 2002; Slimestal et al ., 2007). Allium cepa is beneficial in the treatment of heart diseases, cancers and also diabetes (Formica and Regelson, 1995; Taj Eldin et al ., 2010). Its aqueous suspension alleviates gastric tissue damage (Alqasomi, 2015). However, its role in generation of reactive oxygen species, lipid peroxidation and neutrophil infiltration in gastric tissue is yet to be elucidated. Therefore, this study was aimed at investigating the effects of Allium cepa on gastric neutrophils infiltration in ethanol-induced gastric injury since neutrophils have been implicated in the aetiology of gastric tissue damage.

\section{MATERIALS AND METHODS}

\section{Experimental animals}

Twenty four male Wister rats (with weight ranging from $150-200 \mathrm{~g}$ ) were used for this study. The animals were acclimatized for 2 weeks in animal Holdings of the Department of Physiology, Ladoke Akintola University of Technology, Ogbomoso, Oyo State, Nigeria. Animals were cared for according to United States National Institute of Health Guidelines for the Care and Use of Laboratory Animals (NIH publication No 85-23) and allowed free access to animal feed and water. The animals were grouped into four and treated as follows; Group one served as control, Allium cepa group were treated with Allium cepa juice $(1.0 \mathrm{ml} /$ $100 \mathrm{~g}$ body weight) for 28 days. Allium cepa + ethanol group were also treated as Allium cepa group but also administered $0.2 \mathrm{ml}$ of $98 \%$ (v/v) ethanol per $23 \mathrm{~g}$ body weight and then sacrificed 4 hours later on the $28^{\text {th }}$ day. Ethanol group were administered $98 \%$ (v/v) ethanol $(0.2 \mathrm{ml} / 23 \mathrm{~g}$ body weight) four hours before sacrifice on the $28^{\text {th }}$ day of the experiment.

\section{Preparation of Allium cepa juice.}

Allium cepa juice was prepared as earlier reported (Ige and Akhigbe, 2013). Briefly, Allium cepa bulbs were purchased from local market in Ogbomoso, Oyo state, Nigeria. They $(200 \mathrm{~g})$ were peeled and rinsed thoroughly with distilled water and air dried and then blended. The juice was then filtered using a sterile and tight sieve. The juice was prepared daily.

\section{Induction of Gastric Injury}

Induction of gastric injury was done by administration of $(0.2 \mathrm{ml} / 23 \mathrm{gBW}$ of $98 \%(\mathrm{v} / \mathrm{v})$ ethanol) after the animals have been fasted for 36 hours according to lge et al., (2012a).

\section{Evaluation of Gastric tissue damage}

Stomachs were opened along greater curvature, rinsed in normal saline and examined using magnifying lens (Hi-Tech Zone, Ningbo, Zhejiang, China). The degree of gastric damage was scored according to Praveen and Paradhasaradhi, (2013) as follows; normal coloured stomach $=0$; red colouration $=0.5$; spot ulcer $=1$; haemorrhagic streak $=1.5$; deep ulcers $=2$; perforation $=3$. The overall total scores divided by 10 was designated the ulcer index. The percentage ulcer inhibition was calculated as described by Anosike et al . (2013) using the formula percentage ulcer inhibition $(\% U I)=(1-U t / U c) \times 100$ was used. The gastric wall thickness was measured with the help of a vernier calliper (Mono-Block, Wuxi Numit, Jiefandanglu, Wuxi, Jiangsu. P.R.China).

\section{Preparation of Samples for Biochemical analyses.}

The animals were sacrificed and their blood was collected by cardiac puncture and centrifuged at 3,000 r.p.m high speed refrigerated centrifuge (Gulfex Medical and Scientific, England) the plasma collected was used for biochemical analyses which included superoxide dismutase (SOD), malondialdehyde (MDA), and catalase (CAT). Stomachs were harvested and divided into two. A part was homogenized in phosphate buffer $(\mathrm{pH} 7.0)$ and centrifuged at 4000 r.p.m for ten minutes and the supernatants used for biochemical analyses namely, superoxide dismutase (SOD), malondialdehyde (MDA), and catalase (CAT). The other part was homogenized in phosphate buffer ( $\mathrm{pH}$ 6.0) for the determination of myeloperoxidase (MPO) activity according to Rao et al., (2003). Plasma and tissue SOD, 
CAT and MDA were carried out as previously described (Ige et al , 2012b).

\section{Histological processing and examination}

Histological section was done according to the method of Ogihara and Okabe, (1993). Small portions of the stomach tissues were collected and fixed in $10 \%$ formalin for studying its histoarchitecture. After fixing, it was cut into $5 \mu \mathrm{m}$ sections, and stained with haematoxylin and eosin stain.

\section{Statistical analysis}

Statistical analyses were performed with Graph Pad Prism 5 statistical package. All values were reported as mean \pm S.E.M. Data were analysed by using a one - way analysis of variance (ANOVA) followed by unpaired Student's $t$-test. Values of $P<0.05$ were considered statistically significant.

\section{RESULTS}

Effect of Allium cepa on Gastric tissue Administration of ethanol resulted in gastric injury with manifestation of ulcer and increase in thickness of the gastric wall; treatment with Allium cepa juice significantly ameliorated these effects of ethanol (Table 1).

\section{Effect of Allium cepa juice on Antioxidant status of plasma and Gastric tissue}

There was a significant increase in MDA level and significant decrease in SOD and catalase activities in the plasma and gastric tissue of animals given ethanol alone, pre-treatment with Allium cepa improving the lipid peroxidation status in the plasma and the gastric tissue by significantly increasing the SOD and catalase activities and decreasing the MDA level (Tables 2 and 3$)$.

Table 1: Effect of Allium cepa on Ulcer score, Ulcer index, percentage ulcer inhibition and stomach wall thickness

\begin{tabular}{lllll}
\hline Groups & Ulcer score & Ulcer index & $\begin{array}{l}\text { \% Ulcer } \\
\text { inhibition }(\%)\end{array}$ & $\begin{array}{l}\text { Gastric wall } \\
\text { thickness }(\mathrm{mm})\end{array}$ \\
\hline Control & $0.00 \pm 0.00$ & $0.00 \pm 0.00$ & - & $1.67 \pm 0.11$ \\
Allium cepa & $0.00 \pm 0.00$ & $0.00 \pm 0.00$ & 100 & $1.67 \pm 0.11$ \\
Allium cepa + Ethanol & $0.50 \pm 0.13^{*+}$ & $0.06 \pm 0.01^{*+}$ & 62.5 & $3.17 \pm 0.11^{*+}$ \\
Ethanol & $1.60 \pm 0.19^{*}$ & $0.16 \pm 0.02^{*}$ & 0 & $4.0 \pm 0.12^{*}$ \\
\hline
\end{tabular}

${ }^{+} p<0.05$ vs. ethanol ${ }^{*} p<0.05$ vs. Control.

Table 2: Effect of Allium cepa juice on Plasma Antioxidant status

\begin{tabular}{llll}
\hline Groups & $\mathrm{SOD}(\mathrm{U} / \mathrm{g})$ & $\mathrm{CAT}(\mathrm{U} / \mathrm{mg})$ & $\mathrm{MDA}(\mu \mathrm{mol} / \mathrm{g})$ \\
\hline Control & $1.64 \pm 0.04$ & $0.39 \pm 0.04$ & $0.31 \pm 0.02$ \\
Allium cepa & $1.73 \pm 0.04^{*}$ & $0.49 \pm 0.04^{*+}$ & $0.27 \pm 0.03^{*}$ \\
Allium cepa + ethanol & $1.64 \pm 0.06^{+}$ & $0.41 \pm 0.03^{+}$ & $0.32 \pm 0.02$ \\
Ethanol & $1.31 \pm 0.06^{*}$ & $0.30 \pm 0.03^{*}$ & $0.34 \pm 0.03^{*}$ \\
\hline
\end{tabular}

${ }^{+} p<0.05$ vs. ethanol ${ }^{*} p<0.05$ vs. Control.

Table 3: Effect of Allium cepa juice on Antioxidant status in Gastric tissue.

\begin{tabular}{llll}
\hline Groups & $\mathrm{SOD}(\mathrm{U} / \mathrm{g})$ & $\mathrm{CAT}(\mathrm{U} / \mathrm{mg})$ & $\mathrm{MDA}(\mu \mathrm{mol} / \mathrm{g})$ \\
\hline Control & $1.59 \pm 0.07$ & $0.36 \pm 0.04$ & $0.38 \pm 0.05$ \\
Allium cepa & $1.73 \pm 0.04^{*}$ & $0.43 \pm 0.04^{*}$ & $0.33 \pm 0.06$ \\
Allium cepa + Ethanol & $1.62 \pm 0.06^{+}$ & $0.34 \pm 0.04^{+}$ & $0.83 \pm 0.10^{*+}$ \\
Ethanol & $1.35 \pm 0.06^{*}$ & $0.23 \pm 0.03^{*}$ & $1.19 \pm 0.01^{*}$ \\
\hline
\end{tabular}

${ }^{+} \mathrm{p}<0.05$ vs. ethanol $* \mathrm{p}<0.05$ vs. Control. 
Effect of Allium Cepa on Myeloperoxidase activity of ethanol-induced gastric injury

Administration of ethanol significantly $(p<0.05)$ increased the MPO activity when compared with the control, but there was no significant ( $p>0.05$ ) difference in MPO activity in the Allium cepa group when compared with control. MPO activity was significantly $(P<0.05)$ higher in
Allium cepa + ethanol group when compared with the control. The MPO activity of the Allium cepa + ethanol group was significantly lower ( $p>0.05$ ) compared to the ethanol group (Figure 1)

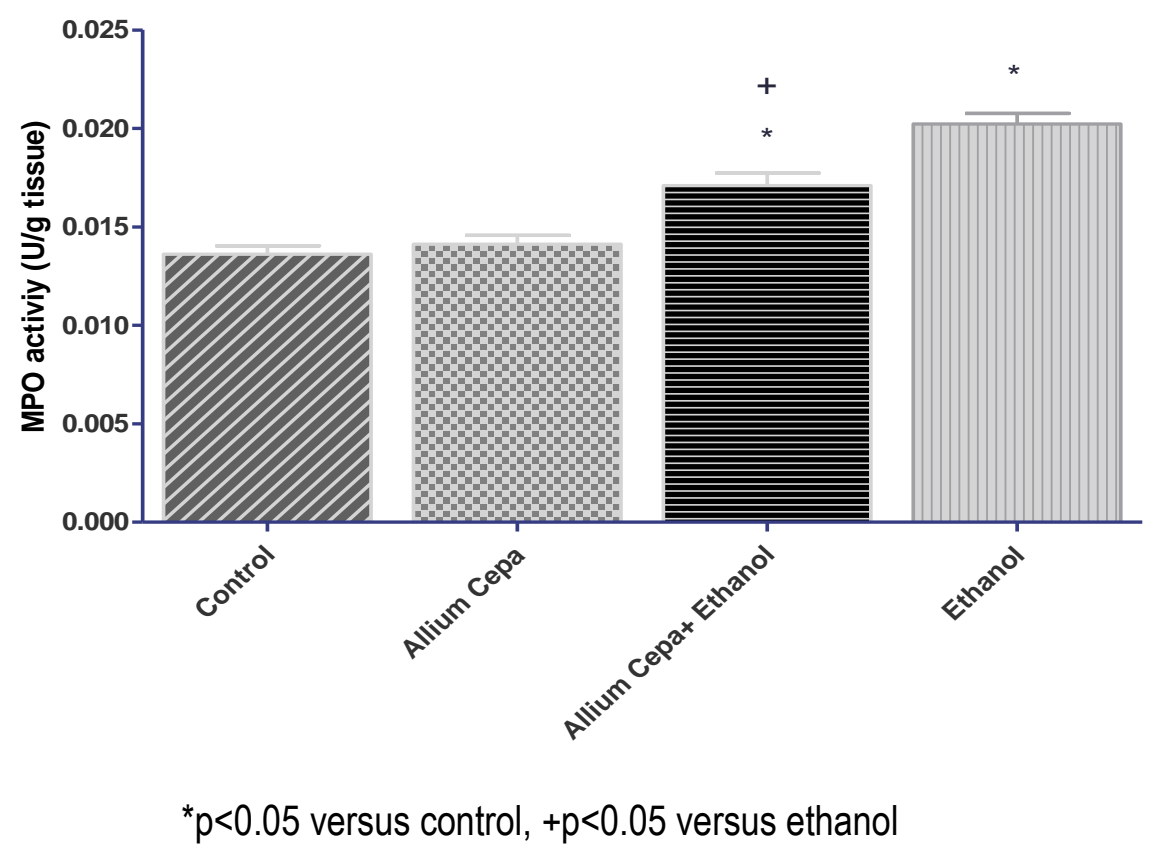

Figure 1: Effect of Allium cepa Juice on Myeloperoxidase Activity in Ethanol-induced Gastric Injury in Rats

Effect of Allium cepa juice on the histoarchitecture of the gastric tissues

Histological examination show glandular destruction in the mucosa, fussed external muscle and muscularis mucosa, oedema and infiltration of inflammatory cell in ethanol group, while Allium cepa juice ameliorated the effect of ethanol, thus maintaining the cyto-architecture by decreasing the degree of inflammatory cells infiltration. (A) Control group rat with intact epithelial surface with normal mucosa, submucosa and muscularis layers. (B) Allium cepa group rat with no histological modifications in the tissue layers. (C) Allium cepa + ethanol group rat showing mild enlargement of the epithelia, mild glandular destruction and mild infiltration of inflammatory cells. (D) Ethanol group rats showing glandular destruction in the mucosa, fussed external muscle and muscularis mucosa, edema and infiltration of inflammatory cell. (black arrow, mucosa; yellow arrow, inflammatory cell).

\section{DISCUSSION}

This study seeks to elucidate the preventive effects of Allium cepa juice on ethanol induced gastric injury in rats. This study finds that treatment with ethanol resulted in gastric injury and this is in agreement with previous studies (Szabo et al., 1991; Ige et al., 2012a). The gastric injury produced was characterized by ulcer, gastric neutrophil infiltration and decreased gastric antioxidant activities. This study also reveals that pre-treatment with Allium cepa significantly decreased gastric damage caused as a result of ethanol administration and increased the percentage ulcer inhibition. Not only that, it significantly decreased the MDA which is a marker for involvement of Allium cepa in the inhibition of gastric lipid peroxidation. 


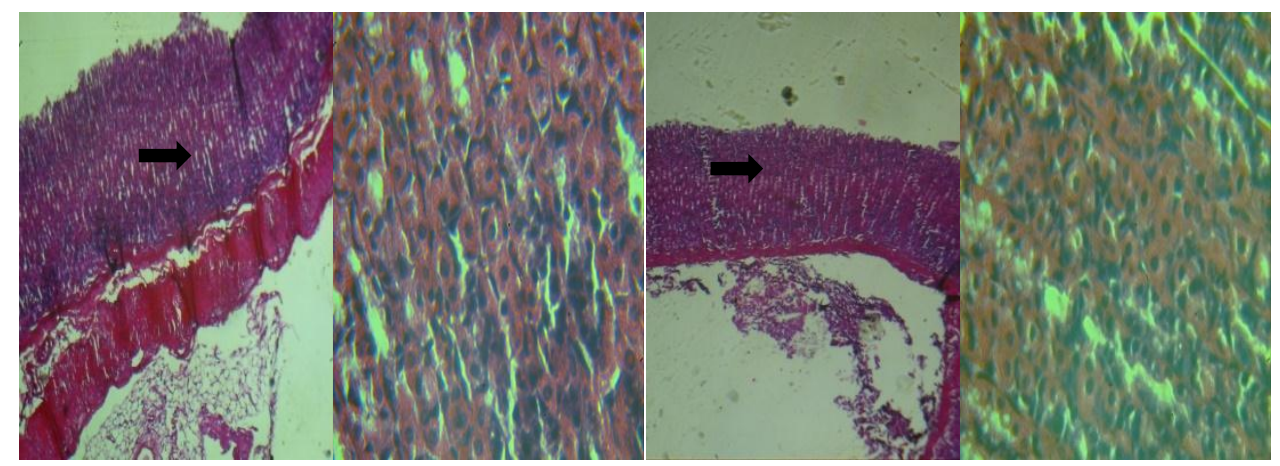

A

B

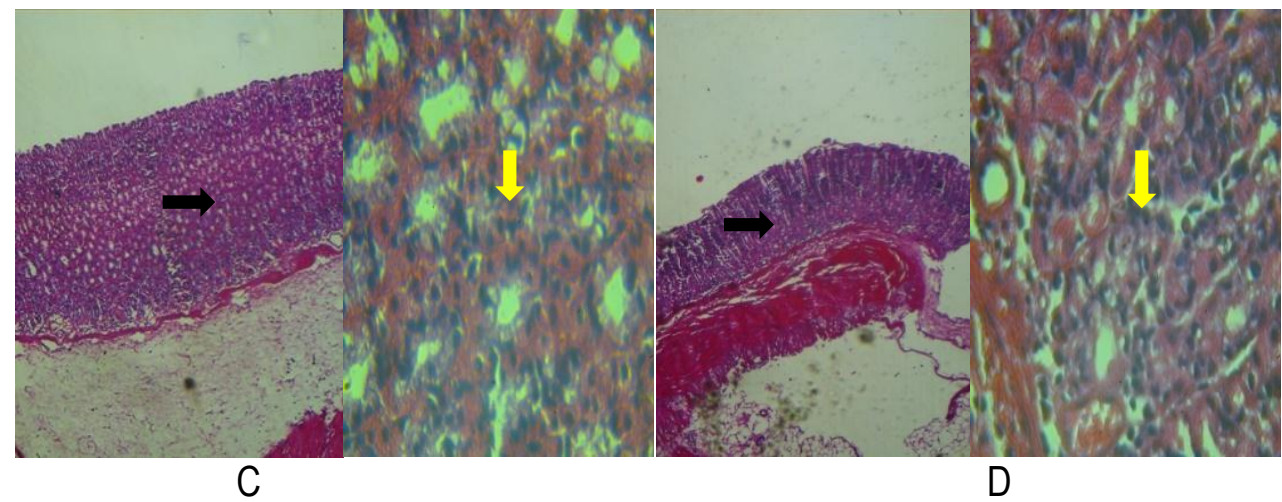

Figure 2: Photomicrograph of the effect of Allium cepa on gastric tissue. Haematoxylin Eosin, $X 40$ and 400

Gastric injury pathogenesis has been known to involve neutrophils (Wallace et al.,1996). Injury produced by neutrophils occurs as a result of their capacity to produce Reactive Oxygen Species (ROS), (Wallace et al., 1992). Study by Kozol et al., (1994) implicated superoxide in neutrophil-mediated gastric injury. This present study demonstrates that Allium cepa increased gastric antioxidant activities, which is important in the body's defense system (Dhanprakash and Garima, 2007; Hwan et al., 2011), as earlier reported (Ige et al., 2011; Ige et al., 2012b). Likewise Superoxide dismutase (SOD), and catalase (CAT) are part of cellular enzymes that regulate reactive oxygen species such as superoxide, hydroxyl radicals and $\mathrm{H}_{2} \mathrm{O}_{2}$ (Buffinton and Doe, 1995; Furrie et al., 2004). This study finds that treatment with ethanol resulted in decrease gastric antioxidant activities and this is in agreement with previous studies (Liu et al 2012; Arab et al., 2015). This reduction was ameliorated as a result of pretreatment with Allium cepa, this is in consonance with the previous findings where
Allium cepa has been shown to improve oxidative status (Ige et al., 2011, Ige et al., 2012b).

Studies have established the generation of free radicals and the resultant lipid peroxidation in ethanol gastric damage, with ethanol as the pathogenesis (Kvietys et al., 1990; Salim, 1990). Ethanol has also been shown to induce vasoconstriction, followed by sharp arteriolar dilation, thus leading to reperfusion (oxygenradicals generation due to ischemic reperfusion resulted in cellular destruction), (Glavin and Szabo, 1992). Inflammatory mediators which are linked to granulocyte and proteases are released, thus invoking cascade of activities leading to gastric damage (Tesyssen and Singer, 2003). This occurred due to the production of reactive oxygen species. From the present study, Allium cepa increased the gastric antioxidant activity which resulted in reduction in reactive oxygen species from the neutrophils, hence reducing the tissue damage. 
Malondialdehyde level was examined in gastric tissue as marker of gastric lipid peroxidation in this study, so as to establish the level of tissue damage. MDA was significantly increased with ethanol treatment which confirmed the increase in the tissue damage, this was significantly reduce with Allium cepa pre-treatment. The significant decreases in MDA with Allium cepa pre-treatment confirm its role in ameliorate gastric damage.

Activation of neutrophil leads to generation of reactive metabolites of oxygen (Bilici et al., 2002) and increased myeloperoxidase activities which results in tissue damage (Granger, 1988). In this study, MPO was used to assess the degree of neutrophil infiltration (Xing et al., 2013; Al - Asmari et al., 2016). MPO activity was found to significantly decrease as suggested by our result consequent to pretreatment with Allium cepa.

Histological examination of the gastric tissue also reveals glandular destruction in the gastric

\section{REFERENCES}

Al - Asmari, A., Al - Shahrani, H, Al - Masri, N, Al - Faraidi, A, Elfaki, I. and Arshaduddin, M (2016).Vanillin abrogates ethanol induced gastric injury in rats via modulation of gastric secretion, oxidative stress and inflammation. Toxicology reports, 3 : 105-113

Alqasoumi, S. (2015). The use of Onion (Allium cepa L.) treatment can mitigate gastric mucosal injury in rats. Issues in Biological Sciences and Pharmaceutical Research, 3(10): 107114

Anosike, C. A. and Ofoegbua, R.E. (2013). Anti-ulcerogenic activity of the methanol extract of Ceiba pentandra stem bark on indomethacin and Ethanol-induced ulcers in rats. International journal of Pharma Sciences, 3(3): 223-228. 223

Arab, H.H., Salama, S.A., Omar, H.A., Arafa, E.-S.A. and Maghrabi I.A. (2015). Diosmin protects against ethanolinduced gastric injury in rats: novel mucosa and inflammatory cells infiltration in ethanol group. This is in agreement with previous studies (Ige et al., 2012a; Al - Asmari et al., 2016), where administration of ethanol resulted in inflammatory cells infiltration and loss of glandular cells in the gastric mucosa. Pre-treatment with Alliums cepa juice reduced these effects and this is in consonance with previous studies (Ige et al ., 2011; Ige et al., 2012b), where Allium cepa has been shown to ameliorate tissue injury.

The MPO and histological results obtained from this study substantiated the fact that there was a significant decrease in the infiltration of neutrophil due to pre-treatment with Allium cepa. This study demonstrates the ameliorative effect of Allium Cepa in ethanol-induced gastric injury probably by reduction in gastric neutrophils infiltration and increased antioxidant activities.

anti-ulcer actions. PLoS One, 10: p.e. 0122417

Bilici, D., Süleyman, H., Banoğlu, Z.N., Kiziltunç, A., Avci, B., Çiftçioğlu, A. et al. (2002).Melatonin prevents ethanolinduced gastric mucosal damage possibly due to its antioxidant effect. Digestive Diseases and Sciences, 47: 856-61

Buffinton, G.D. and Doe, W.F. (1995). Depleted mucosal antioxidant defenses in inflammatory bowel disease. Free Radical Biology and Medicine, 19(6): 911-918.

Dhanprakash, B.N. and Garima, U. (2007). Antioxidant and free radical scavenging activities of phenols from onion (Allium cepa). Food Chemistry, 102:13891393.

Formica, J.V. and Regelson, W. (1995). Review of the biology of Quercetin and related bioflavonoids. Food and Chemical Toxicology, 33(12):1061-80.

Furrie, E., Macfarlane, S., Cummings, J.H. and Macfarlane, G.T. (2004). Systemic antibodies towards mucosal bacteria in ulcerative colitis and Crohn's disease 
differentially activate the innate immune response. Gut, 53: 91-98.

Glavin, G.B. and Szabo, S.(1992). Experimental gastric mucosal injury: laboratory models reveal mechanisms of pathogenesis and new therapeutic strategies. FASEB Journal, 6: 825-31.

Granger, D.N. (1988). Role of xanthine oxidase and granulocytes in ischemiareperfusion injury. American Journal of Physiology - Heart and Circulatory Physiology, 255:H1269-H1275.

Griffiths, G., Trueman, L., Crowther, T. and Thomas, B. (2002). Onions: a global benefit to health. Phytotherapy Research, 17(7): 603-615.

Hajrezaie $M$, Salehen $N$, Karimian $H$, Zahedifard M, Shams K, Batran R.A, et al. (2015). Biochanin A Gastroprotective Effects in EthanolInduced Gastric Mucosal Ulceration in Rats. PLOS ONE, 10(3): e0121529. doi:10.1371/journal.pone.0121529

Hwan, P.B., Khanal, T., Choi, J.M., Chung, Y.C. and Jeong, H.G. (2011). Anthocyanins from purple sweet potato attenuate dimethylnitrosamine-induced liver injury in rats by inducing Nrf2-mediated antioxidant enzymes and reducing COX-2 and iNOS expression. Food and Chemical Toxicology, 49: 93-99.

Ige, S.F., Akhigbe, R.E., Olaleye, S.B. and Adeyemi, J.W. (2012a). Gastroprotective potentials of the methanolic extract of Garcinia kola in rats . International Journal of Medicine and Biomedical Research, 1(3):172178

Ige, S.F., Olaleye, S.B., Akhigbe, R.E., Akanbi, T.A., Oyekunle, O.A. and Udoh, U.S. (2012b). Testicular toxicity and sperm quality following cadmium exposure in rats: Amelorative potentials of Allium cepa. Journal of Human Reproductive Sciences, 5:37-42.

Ige, S.F. and Akhigbe, R.E. (2013). Common onion (Allium cepa) extract reverses cadmium-induced organ toxicity and dyslipidaemia via redox alteration in rats. Pathophysiology, 20: 269-274
Kangwan, N., Park, J.M., Kim, E.H. and Hahm, K.B. (2014). Quality of healing of gastriculcers: Natural products beyond acid suppression. World Journal of Gastrointestinal Pathophysiology, 5(1): 40-47.

Kozol, R., Kopatsis, A., Fligiel, S.E., Czanko, R. and Callewaert, D. (1994). Neutrophilmediated injury to gastric mucosal surface cells. Digestive Diseases and Sciences, 39(1):138-44.

Kvietys, P.R., Twohig, B., Danzell, J. and Specian, R.D. (1990). Ethanol-induced injury to the rat gastric mucosa. Role of neutrophil and xanthine oxidasederived radicals.Gastroenterology, 98: 909-20

Guslandi, M. (1987). Effect of Ethanol on the Gastric Mucosa. Digestive Diseases, 5(1): 21-23.

Liu, Y., Tian, X., Gou, L., Fu, X., Li, S., Lan, N. and Yin, X.. (2012). Protective effect of I-citrulline against ethanol-induced gastric ulcer in rats. Environmental Toxicology and Pharmacology, 34:280287

Main, I.H. and Whittle, B.J R. (1975). Investigation of the vasodilator and antisecretory role of prostaglandins in the rat gastric mucosa by use of nonsteroidal anti-inflammatory drugs. British Journal of Pharmacology, 53: 217-224.

Mowat, A.M. and Viney, J.L. (1997). The anatomical basis of intestinal immunity. Immunological Reviews, 156: 145-66.

O'Connor, A. and O'Moráin, C. (2014). Digestive function of the stomach. Digestive disease, 32(3):186-91.

Ogihara, Y. and Okabe, S. (1993). Effect and mechanism of Sucralfate on healing of acetic acid induced gastric ulcers in rats. Journal of Physiology Pharmacology, 44:109-18.

Oliveira, C.P., Kassab, P., Lopasso, F.P., Souza, H.P., Janiszewski, $M$, et al. (2003). Protective effect of ascorbic acid in experimental gastric cancer: reduction of oxidative stress. World 
Journal of Gastroenterology, 9: 446448.

Onasanwo, S.A., Neetu S., Olaleye S.B. and Gautam P. (2011). Anti-ulcerogenic and proton pump $\left(\mathrm{H}^{+}, \mathrm{K}^{+}\right.$ATP) inhibitory activity of Kolaviron from Garcinia kola Heckel in rodents. Indian Journal of Experimental Biology, 49:461-468.

Ozer, S., Elif, T., Meral, Y., Can E., Sule C., Berrak, Y. and Goksel, S. (2008). Antioxidant Effect of Alpha-Lipolic Acid against Ethanol-Induced Gastric Mucosal Erosion in Rats. Pharmacology, 81(2):173-80.

Praveen, P. S., and Pardhasaradhi, P. (2013). Preliminary phytochemical investigation and anti-ulcer activity of aerial parts of Ruellia tuberosaL.(Acanthaceae) in male Wistar rats. International Journal of Pharmacy and Biomedical Research, 4(3): 145-148.

Rao, V.S.N., Paiva L.A.F., Santos F.A., daSilva R.M, Gurgel L.A., deSousa E.T., and Silveira E.R. (2003). Anti-inflammatory effects of ternatin, a flavonoid from egletes viscose less; in the rat model of colitis induced by acetic acid. Boletin Latinamericano y del Caribe de Plantas Medicinales y Aromatica, Julio, ano. 2(004): 48-51

Salim, A.S. (1990). Removing oxygen-derived free radicals stimulates healing of ethanol induced erosive gastritis in rat. Digestion, 47: 24-8.

Slimestad, R., Fossen, T. and Vagen, I.M. (2007). Onions: a source of unique dietary flavonoids. Journal of Agricultural and Food Chemistry, 55(25): 10067-10080

Sumbul, S.,. Ahmad, M.A., Mohd, A. and Mohd. A.(2011). Role of phenolic compounds in peptic ulcer: an overview. Journal of Pharmacy and Bioallied Sciences, 3:361-367

Suzuki, Y., Hayachi, M., Ito, M. and Yamagani, T. (1976). Anti-ulcer effect of Cetraxate on various experimental gastric ulcer in rat. Japanese Journal of Pharmacology, 26: 471-480
Szabo, S. (1991). Gastroduodenal mucosal injury- acute and chronic: pathways, mediators, and mechanisms. Journal of Clinical Gastroenterology, 13: Suppl 1: S1-8.

Taj Eldin, I.M., Ahmed, E.M. and H.M.A Elwahab. (2010). Preliminary study of the clinical hypoglycemic effect of Allium cepa (Red Onion) in Type 1and Type 2 diabetics patients. Environmental Health Insights, 4: 71-77

Teyssen, S. and Singer, M.V. (2003). Alcoholrelated disease of the oesophagus and stomach.Best Practice \& Research Clinical Gastroenterology, 17: 557-573.

Viana, A.F., Fernandes, H.B., Silva, F.V., Oliveira, I.S., Freitas, F.F., Machado, F.D., Costa, C.L., Arcanjo, D.D., Chaves, M.H., Oliveira, F.A., et al. (2013). Gastroprotective activity of Cenostigma macrophyllum Tul. Var. acuminate Teles Freire leaves on experimental ulcer models. Journal of Ethnopharmacology, 150: $316-323$.

Wallace, J.L., Keenan, C.M., and Granger, D.N. (1996). Gastric ulceration induced by non-steroidal anti-inflammatory drugs is a neutrophil dependent process. American Journal of Physiology, 259: $\mathrm{G} 462$ - 7.

Wallace, J.L., Higa, A., Mcknight, G.W. and Maclntyre, D.E. (1992). Prevention and reversal of experimental colitis by a monoclonal antibody which inhibits leukocyte adherence. Inflammation, 16: 343-354.

Wallace, J.L. (2013). Mechanisms, prevention and clinical implications of nonsteroidal anti inflammatory drug-enteropathy. World Journal of Gastroenterology. 19(12): 1861-1876.

Xing, J., Sun, J., Sun J., Hu S., Guo C., Wang M. and Dong Y. (2012). Protective effects of shikimic acid in acetic acid induced colitis in rats. Journal of Medicinal plants Research, 6(10): 2011-2018 